Irish Educational Studies, Vol. 22, No. 2, Autumn, 2003

\title{
UNCERTAINTY, THE MOTHER OF OPPORTUNITY REVIEWING TEACHING AS A WAY OF LIFE IN IRELAND IN THE EARLY $21^{\text {st }}$ CENTURY
}

\author{
Pádraig Hogan

\section{Introduction: Conflicting readings} \\ It was the best of times, it was the worst of times, it was \\ the age of wisdom, it was the age of foolishness, it was \\ an epoch of belief, it was the epoch of incredulity, it \\ was the season of Light, it was the season of Darkness, \\ it was the spring of hope, it was the winter of despair, \\ we had everything before us, we had nothing before us.
}

Charles Dickens, $A$ Tale of Two Cities

Let me begin with a few reflections on the less than happy state of affairs in teaching in Ireland in the last few years. When we think of the contrasting responses among Ireland's teachers to the developments that have taken place in the profession since the issuing of the 1992 Green Paper Education for a Changing World (Govt. of Ireland, 1992), the spectrum of belief, outlook and hope described above by Dickens springs to mind. Looking back over the history of Irish education, it is hard to recall a time when teachers took such fundamentally differing standpoints among themselves in analysing current developments in the profession and in discerning its future prospects.

On the brighter side, many primary teachers believe that recent and ongoing developments point the way at long last to a genuinely promising future for primary teaching in Ireland. These developments include: the advent of the revised curriculum of 1999 , with its new forms of inservice education; the experience to date and the wider potential of initiatives like "Breaking the Cycle" and "Early Start"; and the first stirrings of new developments in early childhood education. In addition, despite serious concerns over the issue of remuneration for school principals, the leadership of the INTO sees some unprecedented opportunities for securing decent advances in the historic shift to a benchmarking process for determining teachers' salaries.

If we move to the other end of the spectrum of hope, we find ourselves in the company of sizeable numbers of teachers, especially of secondary teachers, who believe that the reforms of the nineties 
have been significant mainly for the additional burdens they have brought with them, for the market ideology they betoken, for their failure to address issues of payment, and for their alleged potential to subject teachers' work to unparalleled levels of intrusion by agents of the state. From this perspective, moreover, benchmarking is seen as the back door by which a new regime of surveillance and performance-related pay, already a reality in other countries, might be installed in Ireland.

I should emphasise from the outset that I am not placing all primary teachers at the hopeful end of the spectrum and all secondary teachers at the other. Indeed, more than a few primary teachers take a less sanguine view of the future of the profession than the leadership of the INTO has been taking. On the other hand, there are several among the ranks of second-level teachers (including secondary and VEC) who believe that the prospects for both pay and the future of the career more generally would look decidedly brighter if the teaching profession as a whole were to be united within the Irish Congress of Trade Unions and were to present a common front to the Department of Education and Science, as it did in the "Teachers United" campaign of 1986.

My purpose in offering these introductory observations is to highlight some sharp contrasts in the analysis of current events and trends by different teachers, or different groups of teachers. This contrast in analysis can be very roughly described as a contrast between perspectives which spring from an acceptance of the "partnership model" of conducting public affairs and perspectives which are deeply sceptical of this model. The contrast itself becomes abundantly evident when we review the mixed fortunes of educational reforms in our own country in the last decade, and when we consider the conduct of the teachers' pay campaigns over the last few years. In this connection, the news reports, feature articles and letters columns of the national daily papers that span these years make a very interesting study for anyone who is keen to research in detail how things stand with teaching as a way of life in the Republic at the start of the twenty-first century. The archives of the teachers' unions and interviews with key figures will no doubt provide even more illuminating material for historians in the years ahead.

Here, however, we must confine ourselves to a narrower canvas and must focus on a few central questions. 
1. Why do different groups of teachers take such contrasting stances in their analyses of the current educational reforms and the future prospects of teaching?

2. Have those who have gone along with the "partnership" model sold the soul of teaching and acquiesced in a new mercenary creed?

3. Have those who have broken with the partnership model been blinded by their own prejudices to the heart of what is happening in the educational reforms and in the new procedures for appraising teachers' pay?

The latter two questions have featured prominently in recent debates, not so much as questions but as mutual accusations. The first question, by contrast, has scarcely been raised. Unlike the second and third questions, the first is essentially exploratory in character. Its investigation might therefore help to provide a more sober and satisfactory context than we have been accustomed to for considering the kinds of issues that arise in the other two questions. So let us now get to work on this investigation, beginning with a few pertinent historical reflections.

\section{A backward glance}

The decades between independence and the late nineteen sixties in Ireland could be described largely as a period of continuity, even of acknowledged certainties, in the prevalent moral and social order. This was clearly an era of established hierarchies, of official pieties, and also some would argue, of cultural and economic stagnation (Whyte, 1971, Brown, 1981). A few years ago Tom Mullins presented some very interesting sketches of what it was like to be a teacher in Ireland during these decades in his address at an ESAI Annual Conference "Masters and Miscreants: Images of the Teacher in Anglo-Irish Literature." (Mullins, 1997). Among the works he surveyed were writings by Francis McManus, John McGahern, Brian Friel and Bryan MacMahon, that give memorable voice to the experiences of teachers during these decades. (He didn't deliberately omit female authors from his survey. He couldn't find any, a fact that carries disquieting suggestions of its own.) Tom Mullins' reflections sent me searching through this literature and I was struck by an awareness that should have come to me earlier from countless conversations with teachers. What struck me was that the contrast of outlooks that I have mentioned above finds its parallel, in some ways its ancestry, in the contrasting reactions of the teachers to the prevailing order illuminated in the literary works to which Mullins directs our attentions. Because 
of constraints of space, I will illustrate by drawing on the example of just two writers: Francis McManus and Bryan MacMahon.

The reflections of schoolmaster John Lee, in McManus's fictional but realistic novel Flow on Lovely River (Mc Manus, 1941), present a revealing, indeed a frightening, picture of the prison into which one's whole identity can be drawn as a teacher when working and living under the surveillance of a bureaucratically-minded inspectorate and a suffocating form of Catholicism. Lee cannot find the courage to resist the Parish Priest's pressure to give up the girl he loves. The priest (who at that time was the school's manager and the master's boss) believes the girl to be an unworthy companion for a teacher in the national school. John Lee's bruised spirit yearns for the respite that the weekend will provide from the cramping everydayness of school life under such a regime. He craves the freedom from "dry adult discipline that seems to have no purpose." But his imaginative capabilities have become so atrophied by his cultural imprisonment that the freedom is wasted when it arrives.

I slipped into Kilkenny this evening for a few detective stories, drugs to send my mind to sleep when the body alone aches for it. To think I feed on those things now exclusively, while once, if I'm not hoodwinking myself, I could savour Shakespeare, Paradise Lost, Keats, and even the razor-edged bardic verse! The blood must run thin now. It must run thin too in some of the men who were trained with me, who gloried in company and rattled out words in feeble, ludicrous, vigorous, wise, topsy-turvy argument as we walked round and round the quadrangle arches of St. Patrick's. Round and round went all the feet, and then out, the most of them, to the quiet places, the Drombridges, where the Sergeant of the Guards forever lays down the law to a fawning publican. You are never yourself afterwards. You are someone else. The schoolmaster, Mr. John Lee. Master Lee. You must be fashioned to a pattern; you must adjust, give in, efface, distort; but above all, you must be fashioned. (McManus, 1941, p. 30)

What McManus is unfolding for his readers here is not just the story of someone who took on some characteristics and mannerisms of the occupational role he had to play. That happens to some extent in most occupations. Rather what happens to the teacher John Lee is something disastrous: the imposition of an identity that is not his own. 
It involves a dispossession of selfhood and its colonisation by something counterfeit, ungenerous and infertile; a tragic loss of what one might have been.

By contrast, Bryan MacMahon's recollections in one of his last books, The Master (MacMahon, 1992), give an account of an active life, a culturally rich life; a life where teaching, with all its frustrations, is experienced more as a source of fulfilment than of disillusion or enslavement. Yet MacMahon is writing autobiographically about the same era and the same system as those written about in the fictional, though realistic, re-creations of McManus. Why is MacMahon's account so different? Any suggestion that he was luckier than most, or that he was a sycophant, can be quickly discarded when one follows in the book the course of some of the serious conflicts in which he became involved (See for instance Chapter Two of The Master).

Speaking of his realisation during his early days as a teacher that he had some promising talent for this work, MacMahon writes insightfully about his stance towards his pupils, and of "the gift that I sensed was latent in each of them" (p. 18). In such a perceptive capacity on the teacher's part lies much of the buoyancy that can sustain the sense of integrity of teaching as a way of life, as distinct for instance from "a job", or even from "a vocation". For what MacMahon calls "the gift that is latent in each" is not easily discovered and nurtured, even by many teachers of long experience. It presupposes more than a few kinds of discernment in the teacher. It is quickly disfigured or eclipsed moreover if the tenor of its development in pupils is assumed to be the property of the church, or the state, or indeed of parents or of teachers. Education, MacMahon came to realise, has an integrity of its own, which is not to be subordinated to the interests of some supposedly higher institution or authority. There is an insight here that no amount of skill-training for teachers can accomplish. In fact, it has more to do with the epiphanies of the everyday in one's self-understanding as a teacher than with what we normally call skills and competencies.

Aware of the unwelcome pressures that he might have to endure in developing to professional maturity his early promise as a teacher, MacMahon adds "I was resolved to exploit it in my own idiom" (p. 2). This led him into wars with his reverend manager, ecclesiastical authorities, the Department of Education and even the Minister for Education. Through all of these conflicts, however; he says "I was conscious of an inner sense of rectitude" (p. 25). This 
inner sense was sometimes provoked to angered action, but it seems to have been a stranger to arrogance or vindictiveness. Whatever accommodations this teacher made were not ones that diminished or disfigured the integrity of his life as a teacher, or of the insights and convictions that informed it.

To understand why an account such as MacMahon's is so different from the more grim accounts of McManus, and of others of more recent times, we must give attention now to some of the features that darken the mood of such latter accounts. This is all the more necessary in an age when the lives of teachers have apparently become less constrained by the religious, moral and cultural restrictions that characterised the historical era we have briefly surveyed above.

Shifting the analysis to the present, therefore, we need to explore the kinds of distress that can come to prevail among teachers when constraints change their historic form and where the buoyancy provided by a vital educational perspective is lost sight of or is otherwise absent.

\section{Sources of distress: resentment and ressentiment}

It is not difficult to understand why bitterness or cynicism should take root in the bruised hearts of teachers whose real talents remained largely unacknowledged, whose good-will was routinely presumed upon, whose sensibilities were incarcerated, whose artistic possibilities were silenced if not extinguished, whose legitimate expectations of promotion were denied, or else granted only to be pressed into servile compliance. The sketch I have just drawn here will be seen by many, if not most, primary teachers as one from which their profession has been progressively, if unevenly, drawing away in recent decades. I suspect, however, that quite a few post-primary teachers will see in it something more than a historical sketch: something which bears some disturbing resemblances to their situation in the present. I should add immediately, however, that the sources of malaise in the case of post-primary teachers are, for the most part, less explicit and more diverse than the twin figures of manager and inspector that, for over a century and a half, often cast long shadows over the work and lives of their primary colleagues.

Consider for instance the following prominent features of postprimary teaching in Ireland at present: a Leaving Certificate curriculum whose basically inflexible design rests in nineteenth century conceptions of learning; a legacy of pedagogical practices 
which offers all too little scope for artistry in teaching; a schooling ethos that has traditionally made much of the concepts of "vocation" and "voluntary commitment", but that has given too little attention to things tangible in return; an assessment regime and its associated "points" machinery that has more often smothered than stimulated originality; an under-resourced system of initial training that has all too often failed to nurture the enduring dispositions and practices that are called for if one is to develop one's promise as a teacher "in one's own idiom". Despite the introduction of the Junior Certificate programme and of programmes like the Transition Year and Leaving Certificate Applied, inimical features like those I have just mentioned remain prominent in the world of Irish post-primary education. The limitations these place on the scope for professional responsibility and its exercise provide more than a few reasons for lasting dissatisfaction, even before one mentions the vexed question of remuneration. This dissatisfaction receives sharper definition of course from the rapid rise (somewhat slowed by current economic downturn) of a new wave of businessmen and women whose salaries and lifestyles have leapfrogged those of the hardworking men and women who were their teachers just ten or fifteen years ago.

Anger and a recognition of the injustice of one's situation can of course be powerful forces for action. But the character and direction of that action will depend on the clarity and accuracy of the understandings that give rise to the feelings of anger. To explain what is at issue here I want to focus for a moment on the distinction between resentment on the one hand and what is called ressentiment on the other. Resentment, in its most healthy form, is a discontentment which we would prefer to be without, but which arises from our perception of an injustice that has been done to us and that calls for some remedial action on our part. Ressentiment, by contrast, can never be healthy. The concept of ressentiment was advanced by Friedrich Nietzsche in the late nineteenth century to describe features of what he saw as the imprisoning morality of the herd - that great mass of people who would never be capable, in his view, of becoming free spirits (see Nietzsche, 1901/1967, pp. 204, 351, 373). It was given a greater precision and explanatory power, however, in the writings of the German philosopher Max Scheler in the early twentieth century (Scheler, 1913/1998). There is now an extensive body of literature on ressentiment in psychology, in sociology, in literary criticism, in theology, as well as in philosophy. But here is Scheler's own explanation of the concept: 
Ressentiment is a self-poisoning of the mind which has quite definite causes and consequences. It is a lasting mental attitude, caused by the systematic repression of certain emotions and affects which, as such, are normal components of human nature. Their repression leads to the constant tendency to indulge in certain kinds of value delusions and corresponding value judgements. The emotions and affects primarily concerned are revenge, hatred, malice, envy, the impulse to detract, and spite. (p. 29)

There are insights here that call for much reflection. Ressentiment arises firstly where the reasons for one's real resentment remain unaddressed, or where a proper recognition of them seems an impossibility in one's situation. Consider for a moment the response of the teacher John Lee to his unhappy circumstances. "You must be fashioned to a pattem", he concludes. "You must adjust, give in, efface, distort; but above all, you must be fashioned". Were he to resist such fashioning, were he to assert his freedom to marry in the face of the Reverend Manager's displeasure, or to assert his intellectual independence in the face of the Department and its inspectors, his job might be at an end. What we have in John Lee's case then looks very close to ressentiment. But it is saved from becoming such by the master's honest, if painful, acknowledgement to himself that he has been defeated, that his true spirit has been lost. Without the frank moral insight that prompts this humiliating admission, one could more easily embrace the comfort of whatever illusions that might disguise, or even obscure the humiliation. Ressentiment would thus be more likely to take root and prosper.

Where the "fashioning" in question is less manifest, however, it is also likely to be more insidious. Ressentiment is at its strongest where one somehow acquiesces in a situation which takes away, behind one's back as it were, something vital in oneself; where one conforms, in an overlooked way, to a sense of personal identity that is more an ascribed than a genuinely discovered one. Again, let us recall, this should not be confused with the unconscious taking-on of some abiding characteristics or mannerisms of one's job and revealing them in one's interpersonal relations more generally. A key point about ressentiment is that oppression of one form or another is central to it, as is the mis-recognition of the true character or source of that oppression. 
Ressentiment can also arise as a significant feature of a group, as distinct from an individual. This occurs within the cultures of organisations, clubs and associations, or more specifically, among the sub-cultures of such associations. Where teaching is concerned, one may find more than a few traces of it in the subcultures of the teachers' unions. This is not to suggest, however, that to be on the radical wing of a trade union or a political party, or any movement for radical change, is necessarily to be part of a culture of ressentiment. One of the clearest illustrations of this point is the highly productive radicalism of Paulo Freire's literacy circles in Brazil and Chile during the nineteen sixties (Freire, 1972). The analysis underlying this radicalism was based on an incisive understanding of certain historical realities: of the ways in which one's humanity might be robbed or disfigured by one's own acquiescence in invidious attitudes and practices that were heretofore "naturally" inherited in one's culture. The important distinction to be drawn then when examining ressentiment as a characteristic of groups is between two different sources of radicalism: on the one hand a radicalism springing from a "culture of silence" that is now beginning to find its genuine voice and, on the other hand, a radicalism springing from a culture of ressentiment properly so called. As the latter is likely to misrecognise or deny the real sources of its discontent, so it is also likely to carry that mis-recognition into its analysis of events and into its political actions. The first kind of radicalism is largely an enabling one, if also politically explosive, in rendering uncertain and vulnerable the long-established certainties of an oppressive status quo. The second kind of radicalism, though scarcely less explosive, may be more corrosive than enabling of one's capacities for analysis and action.

\section{Ressentiment and perceptiveness in the reading of developments}

These points help to shed light on the first of the three questions raised earlier: Why do different groups of teachers take such contrasting stances in their analyses of the current educational reforms and the future prospects of teaching? First of all, they help to show how teaching as an occupation may be more prone to ressentiment than are some other occupations. This is particularly so if oppression is present in one's working life more as an inherent than an occasional feature, and if it takes forms that are more implicit than overt. That is to say; ressentiment is more likely if oppression is embodied in the constrictions on one's lifestyle, or in the restrictions on one's professional autonomy, that are somehow inherited with the job but are also somehow unmentionable. Secondly, the analysis of 
ressentiment highlights the point that unless such fetters on lifestyle, or restrictions on professional discretion, are explicitly identified for what they are and then addressed, ressentiment will find more fertile soil than it otherwise would. Thirdly, while enormous changes in social attitudes in the last two decades have removed many of the shackles on teachers' lifestyles that featured strongly in the past, many inherited professional attitudes and practices have proved less yielding to change, and also less amenable to analysis and proper acknowledgement. And here, as I have suggested earlier, a contrast can be drawn between important developments that have taken place in the professional lives of primary, teachers and the greater influence of the forces of continuity at post-primary level, especially in the case of secondary teachers.

Where one's analysis of events is coloured in some significant degree by ressentiment, one is likely to smell a rat where a more clearsighted analysis might discern a door of opportunity. This is particularly so when change takes the form of a replacement of old certainties by new uncertainties, rather than by the clearly defined order of an authoritative new regime. Change in democratic societies, and in a special way educational change, rarely takes such a clear-cut course. It is not surprising then that a climate of some uncertainty, arising not only from the demise of older forms but also from a plurality of readings of proposed changes and of their import, comes to prevail in educational discourse, at least in the shorter term. Amid such pluralist animation in our own country, it is instructive to study the standpoint taken to the current educational reforms by a very significant, if not a very large, section within the ASTI. This stance may also be shared by minorities in the other teacher unions. In the Irish Times of 12th February 2002, at the height of the industrial action by secondary teachers, some key features of this standpoint were revealed in a feature article by a recent President of the ASTI (O'Sullivan, 2002, p.7). As reported there, this standpoint sees in the now statutory requirements for school plans and annual reports (Education Act 1998, pp. 20 and 21) the introduction of "Thatcherism" into Irish education and sees in the benchmarking process evidence of a "performance indicators" mentality associated with an ideology of competitive individualism. However plausible this stance might appear at first sight, it cannot be substantiated by any rigorous investigation of the history of educational reform in Ireland over the last decade, and all the more so if one introduces an international comparative dimension into this investigation. If one is looking for a context in which such a standpoint finds its force and coherence, I think one has to look to the less benign of the two forms 
of discontent we have just been exploring. In other words, we have here some credible evidence of the kind of radicalism which is more a manifestation of ressentiment than of a healthier and more promising radicalism.

It is becoming increasingly clear that the National Education Convention of 1993 marks a watershed in Irish education: a watershed, broadly speaking, between the lingering prerogatives, powers and privileges of a patriarchal era and the emergent attempts to find structures and procedures for the conduct of education in a modern pluralist democracy (See Coolahan, 1994). In these attempts, the Convention laid foundations for a path of educational reform that is in marked contrast to the paths that were already embarked on for some years in other countries, for instance North America and Britain (for reviews of the latter, see Maclure, 1988). This new path became more explicit in the White Paper of 1995, Charting our Education Future, with its five underlying principles of pluralism, partnership, quality, equality and accountability (Government of Ireland, 1995). These principles were then enshrined in law in the 1998 Education Act. The legislative reforms have continued with acts such as the Qualifications Act of 1999, the Education (Welfare) Act of 2000 and, most importantly for teaching, the Teaching Council Act of 2001. These legal measures have their own shortcomings and omissions, most notably perhaps the Education (Welfare) Act, which is not, for the most part, a product of the extended educational debate which supplied the substance of the other acts. Of course it is also important to stress that accomplishing a programme of legislative change is very different from accomplishing in practice the changes that legislative reforms seek to bring about. Indeed what progress has been made to date in the recent Irish experience of educational reform lies more in the dismantling of an old order than in any decisive advances in consolidating a new one. The outlines of a future public provision for education in a pluralist democracy have of course been furmished in the legislation. But uncertainties of all kinds can be seen to flourish in the interval between formal enactment and effective implementation. Where teachers are concerned, I think this interval can best be regarded as a ferment of productive opportunity. Indeed the suggestion underlying my title is that Ireland's teachers, if incisive thinking and collective efforts can be sufficiently co-ordinated, are well-placed to make historic gains in just such an interval. I would now like to elucidate this suggestion in the remainder of my remarks. 


\section{Discerning the wood and the trees}

When viewed with a historian's eye (if not by an embattled teacher's eye), the educational reforms of the last decade of the old century and the first years of the new can be seen as an attempt to inaugurate a new era in Irish education. It is important to note that these reforms largely reflect, and in turn contribute to, broader social and cultural changes that have been taking place in Irish society, and in public life more particularly. It is worth taking stock of some of these changes at this point, especially those that affect the conduct of education. They include: an accelerating decline in ecclesiastical power; a radicalisation of standpoint among the larger religious congregations (for instance, the emergence of the Conference of Religious of Ireland as a voice of the left during the nineties); the rise of parents' bodies as a national force; a growing tendency among pupils to assert their own opinions and lifestyles and to challenge or confront their teachers. Amid all the turbulence and moral hesitancy occasioned by these changes it is all too easy to miss something crucial. The historic balance of power in Irish education is continuing to shift in ways that deliver increasingly into the hands of teachers themselves unprecedented opportunities for assuming the decisive authorship of their own professional work. One of the initial pieces of evidence for this is the fact that where the procedure for determining teachers' pay is concerned, the ingenuity of teachers' representatives (mainly the INTO in this case) has accomplished something unparalleled among teachers' associations in other countries. In Ireland, the "benchmarking" concept has been effectively shom of its ideological associations with "performance-related pay" and has been recast as a form of appraisal, for salary purposes, of the duties and responsibilities of teaching posts in contemporary society. That is not to say of course that performance drops out of the picture; rather that it becomes linked to the acceptance and implementation of new conditions of service by a group than to judgements by superiors on an individual's performance. When one mentions this feat to teachers in Britain and elsewhere, they are rarely less than incredulous.

There are other important things one should acknowledge here. Firstly, the statutory requirements for school plans and annual reports (Education Act 1998) are giving to schools, and principally to teachers who can work pro-actively and in concert, opportunities for designing anew how their work is to be conceived, carried out and evaluated. This reference to working pro-actively and in concert is crucial. In the absence of such pro-active co-operation, the new scope for professional freedom might lead to principals and other school leaders 
playing a more managerialist than a collaborative role, and to what Andy Hargreaves has called "contrived collegiality" among teachers (Hargreaves, 1994). The fact that parents, trustees and, to some extent, students also have partnership rights in pursuing these new requirements does not alter the fact that the professional authorship of the process lies decisively before the hands of teachers. That there are new responsibilities associated with this - and new rights of appeal for parents and students - is itself a long delayed recognition of a major point: that teaching is a profession with an office and an integrity of its own within a pluralist democracy, as distinct from being a subordinate occupation to be carried on only under the surveillance of a higher authority, such as Church or state.

Secondly, where questions of curricula and assessment are concerned, the single most significant voice on the National Council for Curriculum and Assessment, and of its committees, has invariably been that of teachers. One might raise questions about how that voice might best be used, but the practical reality at present is that no change can be made to curricula or to assessment procedures without the agreement of the teachers (something that teachers elsewhere also find difficult to believe). And the corollary of this should not be forgotten. It is that teachers' representative bodies are much more strongly placed than at any time in the past to initiate changes in national assessment procedures, most significantly at post-primary level. This is a crucial point, given what has been said earlier about the disfiguring effects of the inherited assessment system on the quality of learning in second-level schools.

Thirdly, the Teaching Council Act - passed in 2001 and due to come into effect in early 2004 - furnishes opportunities of truly historic proportions, especially when one considers, as we did briefly above, what earlier generations of teachers had to endure in Ireland. The composition of the Council itself and of its major committees, the range of the Council's powers and those of the committees, provide the clearest indication yet of a decisive shift in the balance of power among the major parties in Irish schooling. An exploration of the new powers of teaching as a profession arising from this act - including the power to address the gender imbalance that has grown within it should bring to light a range of additional promising possibilities. It would require a separate investigation however and is beyond our scope here.

I am emphasising then the promising significance of the shifting balance of power in Irish education, notwithstanding the 
recent divisiveness among teachers over the reforms and over the strategies to be pursued for better salaries. In speaking of promising prospects, I am aware of course of some counter currents. Firstly, there is the issue of a recent loss of respect among sizeable sections of the public for teachers, arising mainly from some specific actions taken during the industrial dispute between the ASTI and the Department of Education and Science. More broadly, higher levels of education and awareness in the population at large mean that there is now a greater readiness than in former times to challenge the actions of professionals of all kinds, including teachers. Secondly, there is the reality of a new international utilitarianism, in education as in other domains, that presents itself in ever more attractive attire. (For instance the European White paper of 1996, Teaching and Learning: Towards the Learning Society, dissolves the distinction between education and training and lays foundations for EU measures to fund a new commercialisation of education.) In relation to the first of these two counter-currents, one does not need to be a historian to realise that it takes more than one acrimonious breakdown for the teaching force as a whole to lose the respect of successive generations of parents. And it is clearly healthier for both teachers and parents if neither regards the other with either awe or condescension. In relation to the second point, Irish schools' experience to date with EU programmes shows how many utilitarian incursions can be turned to fruitful cultural effect by artful, articulate teachers; not by challenging their ideological colour but by interpreting them with a businesslike ingenuity that makes them serve the educational benefit of the students. But the point remains that counter-currents such as these underline the necessity for a vigilant eye by teachers on any tendency towards complacency among their own ranks, or towards selfinsulation from the different pulses and moods of life outside the school.

To identify and to avail of the historic opportunities that I have suggested are now arising does not mean that teachers have to adopt a uniformity of outlook. In any effort to impose such a uniformity, unions would have to engage in the coercive practices formerly engaged in by many church authorities. Diversity and originality are to be prized, not discouraged, among teachers. What is essential however is that teachers subscribe to a unity of purpose and action, or if you prefer, a harmony in purpose and in action, that is informed by an analysis that takes pains to be clear-sighted and self-critical. We saw something of this unity in the "Teachers United" campaign of the eighties. Its renewal and its cultivation are not only urgent just now. They would also be particularly promising just now. 


\section{REFERENCES}

Brown, T. (1981) Ireland: A Social and Cultural History 1922-1985, London: Fontana.

Coolahan, J. (ed.) (1994) Report on The National Education Convention, Dublin: The Stationery Office.

Dickens, C. (1859/1989) A Tale of Two Cities, London: Penguin.

European Commission (1996) Teaching and Learning: Towards the Learning Society, White Paper on Education and Training, www.europa.eu.int/comm/education/lb-en.pdf.

Freire, P. (1972) Cultural Action for Freedom, London: Penguin.

Government of Ireland (1992) Education for a Changing World, Green Paper on Education, Dublin: The Stationery Office.

Government of Ireland (1995) Charting our Education Future, White Paper on Education, Dublin: The Stationery Office.

Government of Ireland (1998) Education Act, Dublin: The Stationery Office.

Government of Ireland (1999) Primary School Curriculum, Dublin: The Stationery Office.

Government of Ireland (2000) Education (Welfare) Act, Dublin: The Stationery Office.

Government of Ireland (2001) Teaching Council Act, Dublin: The Stationery Office.

Hargreaves, A. (1994) Changing Teachers, Changing Times: Teachers' work and culture in the postmodern age, London: Cassell.

Maclure, S. (ed.) (1998) Through the Revolution and Out the Other Side, a special issue of the Oxford Review of Education, Vol. 24, No.1.

MacMahon, B. (1992) The Master, Dublin: Poolbeg Press.

McManus, F. (1941) Flow on Lovely River, Dublin: Talbot Press.

Mullins, T. (1997) Masters and Miscreants: Images of the Teacher in Anglo-Irish Literature, Irish Educational Studies, Vol. 16, pp.28-39.

Nietzsche, F. (1901/1967) The Will to Power, trans. Kaufmann, W., New York: Vintage.

O'Sullivan, B. (2002) Why we Reject the Application of Thatcherism to Education, The Irish Times, Education and Living supplement, 12 February 2002, p.7.

Scheler, M. (1998/1913) Ressentiment, trans. Coser, L. B. and Holdheim, W. W., Milwaukee: Marquette University Press.

Whyte, J. H. (1980) Church and State in Modern Ireland 1923-1979, Dublin: Gill and Macmillan. 